\title{
Short term results of total knee arthroplasty in tertiary rural tier three government medical college and hospital
}

\author{
Ansari Muqtadeer Abdul Aziz ${ }^{1}$, Nair Pradeepkumar Sasidharan ${ }^{1 *}$, Punit S. Malpani²
}

\begin{abstract}
${ }^{1}$ Department of Orthopaedics, Government Medical College and Hospital, Aurangabad, Maharashtra, India
${ }^{2}$ Department of Orthopaedics, Kamal Nayan Bajaj Hospital, Aurangabad, Maharashtra, India
\end{abstract}

Received: 28 May 2020

Revised: 11 June 2020

Accepted: 12 June 2020

\author{
*Correspondence: \\ Dr. Nair Pradeepkumar Sasidharan, \\ E-mail: nairpradeep1234@gmail.com
}

Copyright: (c) the author(s), publisher and licensee Medip Academy. This is an open-access article distributed under the terms of the Creative Commons Attribution Non-Commercial License, which permits unrestricted non-commercial use, distribution, and reproduction in any medium, provided the original work is properly cited.

\begin{abstract}
Background: The objective of the study was to assess the clinical and functional outcome of total knee arthroplasty (TKA) using posterior cruciate stabilizing (PS) design in tertiary rural government hospital with limited infrastructure using the Western Ontario and McMaster Universities Osteoarthritis Index (WOMAC) score and to offer a low cost option and assess post-operative pain relief in rural poor of the society and to compare the WOMAC score pre and postoperatively.

Methods: The study was conducted on patients who have undergone primary total knee arthroplasty in Department of Orthopaedics, Government Medical College and Hospital, Aurangabad from December 2018 to December 2019. The patients were assessed using the WOMAC score and X-rays. These evaluations were performed at 3, 6 and 12 months follow up visits.

Results: At 1 year follow up of 30 knees, the average pre-op WOMAC score of 79.5 improved to an average post-op score of 42.3. And knee flexion increased from 96.3 degree to 108.5 degrees both of which with a p value $<0.0001$ are statistically significant. One patient each had wound dehiscence and superficial infection. Patient satisfaction after the procedure was good-both in unilateral and staged bilateral TKA.

Conclusions: TKA reduces knee pain significantly and improves the functional ability of the patient. And to be able to do so in a tertiary government rural setup with no laminar airflow and with such great efficacy and minimal complications bodes well for the number of people living in rural areas suffering from knee pain.
\end{abstract}

Keywords: Clinical and functional outcome, WOMAC score, Total knee arthroplasty, Posterior stabilizing design

\section{INTRODUCTION}

Total knee arthroplasty (TKA) is a procedure wherein the damaged knee joint is replaced by an artificial joint made up of a femoral and tibial component with an articular insert. The commonest causes of severe knee pain are osteoarthritis, rheumatoid arthritis and post-traumatic arthritis out of which TKA is done most commonly for osteoarthritis of the knee causing severe pain and affecting the functional ability of the person. The overall prevalence of osteoarthritis of knee in the world was about $28.7 \%$ with female gender, obesity, old age and sedentary work contributing as risk factors. ${ }^{1,2}$ The TKA era in the world started in 1973 making its way into the Indian setup some years later. $^{3}$ The patients undergoing TKA in rural government setup are quite few as compared to the urban population. Hence most patients were subjected to medical treatment, lifestyle modification, weight reduction and exercise as management of severe knee pain caused by arthritis. ${ }^{4}$ With the development of better facilities and increasing awareness among the rural population, TKA has emerged as a potential treatment option for severe 
arthritis. As a tertiary care center catering to a large population of low-middle class and rural families with limited infrastructure, there was a need to assess the actual benefit of TKA in improving the quality of life of these people who were not adequately managed with non surgical methods. ${ }^{5}$ As with every surgical procedure, TKA has its own set of complications like Infection, thromboembolism, patellofemoral complications, periprosthetic fractures, joint instability, malalignment, stiffness and osteolysis of the knee. ${ }^{6}$ In this study we attempt to offer a pain-free surgical option of TKA at low cost to rural population in tertiary rural government setup for painful osteoarthritic knees to improve quality of life. ${ }^{7}$

This study was done with the objective of assessing the post-operative pain relief and cost effectiveness of TKA in government set-up in the rural poor and compare the WOMAC score pre and post-operatively.

\section{METHODS}

All patients admitted in Government Medical College and Hospital, Aurangabad for TKA between December 2018 to December 2019 were evaluated for 12 months postTKA. Severe knee pain affecting patient lifestyle was the main indication for surgery. Pain, function and quality of life were evaluated according to the Western Ontario and McMaster Universities Osteoarthritis Index (WOMAC) function score (Table 1). ${ }^{8,9}$ Pre-operative X-rays of knee (standing antero-posterior with single joint weight bearing and lateral view) were taken for assessing and confirming the clinical findings of any deformities. General work-up of the patient was done (complete blood count, liver function test, kidney function test, blood sugar level, prothrombin time, venous doppler of the affected limb, serology testing, 2-D echocardiography) along with any specific investigations if advised by physician and anaesthetist.

There are different implant designs for TKA. In our study femoral component used was posterior stabilized type (both cruciates removed). Tibial component was either an all-poly or modular type and the components were fixed to the bone with the help of cement. And in one case of severe varus deformity, tibial extension rod was used. All the implants used were imported provided by Zimmer (Nexgen), Depuy Johnson and Johnson (P.F.C. Sigma) or Smith and Nephew company (Anthem).

\section{Surgical technique}

The surgery was undertaken in a standard OT with size $6.5 \times 6.5 \times 3.5$ metres with a 2 tonne split AC with no laminar airflow. We restricted the number of staff in the operation theatre - one primary surgeon, one assistant surgeon, one scrub nurse, one implant company person and one anaesthetist. Patient was asked to take bath the night before and the surgical site was painted with betadine solution (5\%) and covered with a sterile pad and bandaged. Intravenous antibiotic (injection piperacillin-tazobactum
4.5 grams (2.25 grams if renal impairment) intravenously or injection linezolid 600 milligrams intravenously) was administered once the night before (12 hours prior to surgery) and the second dose 30 minutes prior to incision. Shaving of skin hair over surgical site was done 10 minutes before surgery. Foley's catheterization was done. Patient was positioned supine with hip and knee flexed to 45 degree. The procedure was carried out under spinal anaesthesia with or without epidural. Tourniquet was applied. Painting of surgical site was done with betadine scrub $(7.5 \%)$.

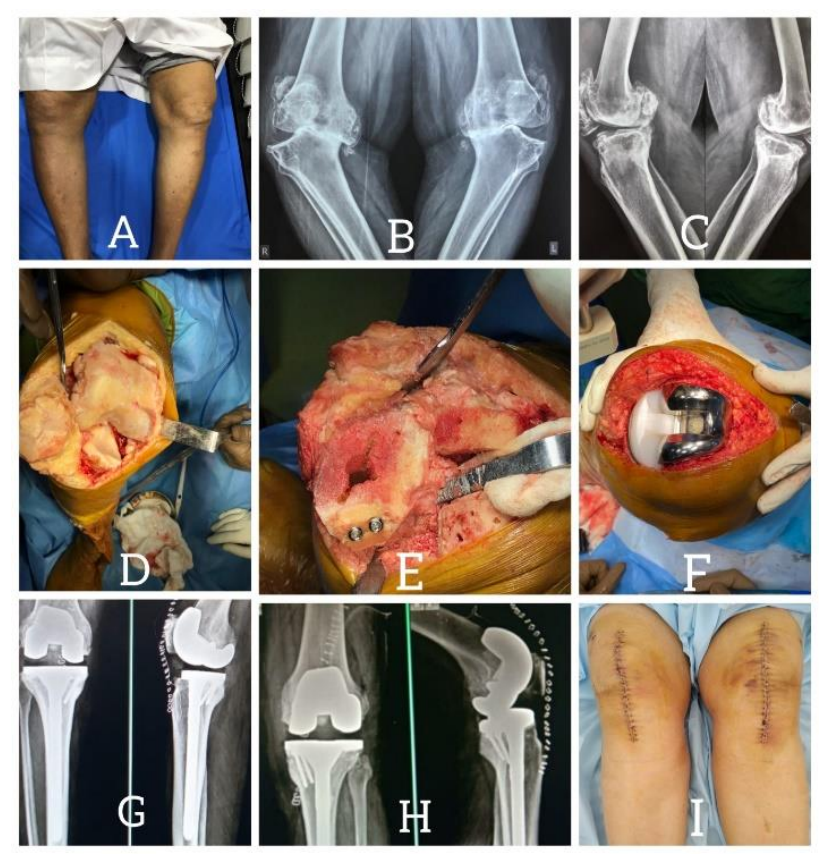

Figure 1: TKA done in a 70 year old severely osteoarthritic patient (A) patient with bilateral genu varus (B) pre-operative antero-posterior X-ray of both affected knees $(C)$ pre-operative lateral $X$-ray of both affected knees (D-F) Intra-operative images of the procedure $(G)$ post-operative antero-posterior and lateral X-ray of right knee $(\mathrm{H})$ post-operative anteroposterior and lateral X-ray of left knee (I) postoperative clinical picture of the patient with corrected varus deformity.
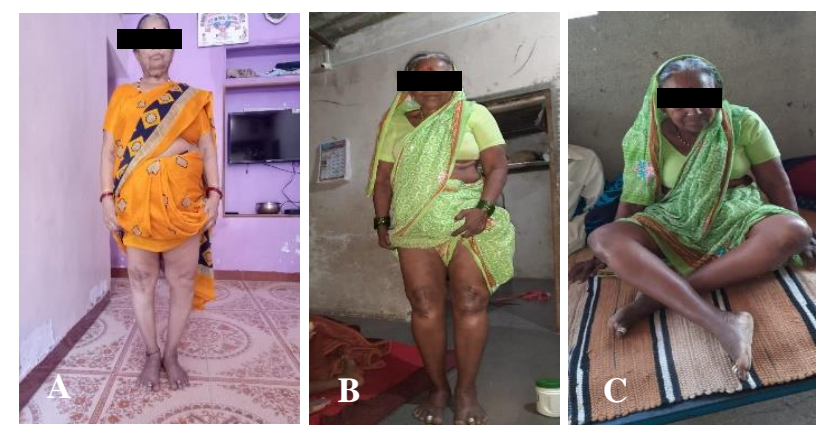

Figure 2: (A) 12 months post-operative clinical picture of unilateral TKA, (B and C) 12 months postoperative clinical picture of a lady with bilateral TKA done. 
Table 1: WOMAC scale.

\begin{tabular}{|c|c|c|c|c|c|}
\hline Criteria & $\mathbf{0}$ & 1 & 2 & 3 & 4 \\
\hline WOMAC pain assessment at & - & - & - & - & - \\
\hline Walking & - & - & - & - & - \\
\hline Stair climbing & - & - & - & - & - \\
\hline Night & - & - & - & - & - \\
\hline Rest & - & - & - & - & - \\
\hline Weight bearing & - & - & - & - & - \\
\hline WOMAC stiffness assessment & - & - & - & - & - \\
\hline In morning & - & - & - & - & - \\
\hline Occurring during the day & - & - & - & - & - \\
\hline \multicolumn{6}{|c|}{ WOMAC physical function assessment (difficulty) } \\
\hline Descending stairs & - & - & - & - & - \\
\hline Ascending stairs & - & - & - & - & - \\
\hline Rising from sitting & - & - & - & - & - \\
\hline Standing & - & - & - & - & - \\
\hline Bending to the floor & - & - & - & - & - \\
\hline Walking on flat & - & - & - & - & - \\
\hline Getting in/out of a car & - & - & - & - & - \\
\hline Going shopping & - & - & - & - & - \\
\hline Putting on socks & - & - & - & - & - \\
\hline Rising from bed & - & - & - & - & - \\
\hline Taking off socks & - & - & - & - & - \\
\hline Lying in bed & - & - & - & - & - \\
\hline Getting in/out of bath & - & - & - & - & - \\
\hline Sitting & - & - & - & - & - \\
\hline Getting on/off toilet & - & - & - & - & - \\
\hline Heavy domestic duties & - & - & - & - & - \\
\hline Light domestic duties & - & - & - & - & - \\
\hline
\end{tabular}

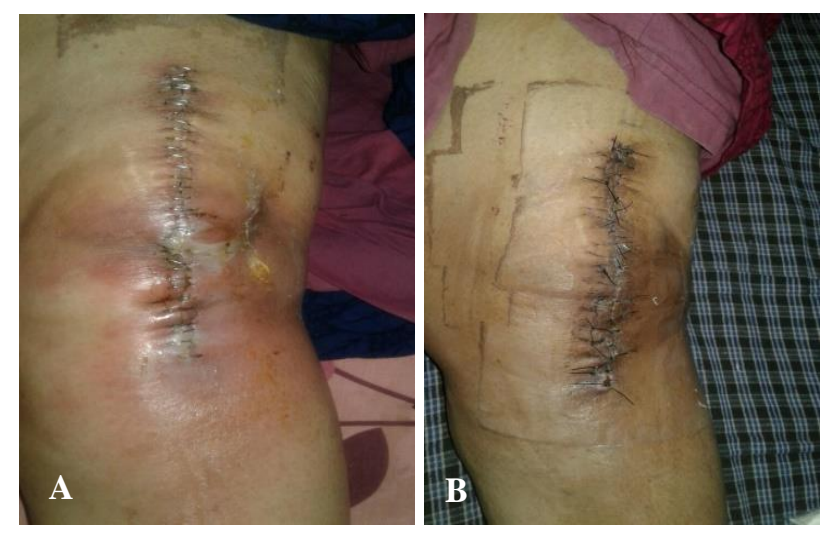

Figure 3 (A and B): Post-operative complication (infection).

Disposable drapes were used to reduce the infection rates. Anterior midline incision of 8-10 inches was taken. Skin flaps were elevated. Soft tissue dissected. Medial parapatellar arthrotomy was done. The patella is subluxed outside the knee area. First with an intramedullary jig distal femoral cut is taken of about 8-9 millimetres. The knee is extended and the spacer is kept near the proximal tibia and marked with the help of a cautery. Then the knee is flexed 90 degrees and tibia is subluxated with the posterior spike carefully placed over the posterior proximal edge of tibia. Extramedullary jig is used and about 8 millimetres of tibial cut is taken with the boom placed over the highest point of lateral tibial plateau. The jig is aligned over tibialis anterior and tibial shin adjusting 3 degrees for posterior slope and over the midpoint of ankle aligning the second ray of foot. Check for extension gap. Then the knee is flexed, antero-posterior sizing of the distal femur is done and the cut is taken over the posterior condyle with the help of the jig. Jig is removed and flexion gap is checked. At this point, it is very important to ensure that both the flexion and extension gaps are the same. Gap balancing is used with measured resection techniques, where we found a postero-medial tibial bone defect in one of our case of severe varus deformity and we did a medial tibial reduction osteotomy. This is the most important step of the procedure to equalize the flexion and extension gap. Once it is confirmed, replace the distal femoral jig and complete all the cuts (anterior cuts, chamfer cuts and notch/box cuts). Now the proximal tibia is prepared to complete the sitting of the keel and the baseplate. Then the trial is done and Knee stability is checked in flexion, extension and mid-flexion. Then the definitive components are implanted with the help of cement - first tibial component is fixed followed by the femoral component. Wound wash is given (pulse lavage is not used to restrict the cost). Trial insert is placed and knee joint is reduced. Then a mop is kept in the surgical wound and bandaged. Tourniquet is released and after removing the mop and bandage, all the bleeders are cauterized. Appropriate final insert is fixed on tibial baseplate. The knee is reduced and flexion extension and varus/valgus stability is confirmed for the final time. Drain tube kept and the wound is closed in layers in midflexion position. Patient is kept in intensive care unit after surgery for one day for observation of vital parameters. Patient's hemogram is tested and if less than $10 \mathrm{gm} \%$ then a point of packed cell volume is administered. Foley's catheter is removed after 12 hours and low molecular weight heparin (enoxaprin) 0.4 grams is administered subcutaneously for 3 days-the first dose starting 12 hours after the surgery for deep vein thrombosis prophylaxis. Drain removed after 12-24 hours. IV antibiotics given for 3 days only as a measure to reduce the costs in rural government setup starting post-operative day- 0 and then shifted to oral antibiotics for further 5 days. Bedside sitting started on day-1. Knee range of motion (ROM) exercises and supported ambulation on walker started on day-2 gradually shifting to unsupported ambulation as tolerated by the patient. Staircase climbing started on day- 4 and patient discharged on day-5 (for unilateral TKA). For bilateral TKA cases, after the first procedure was done, the patient was stabilized and mobilized adequately and the operation on the other leg was done after 10-14 days due to limited infrastructure in government setup.

\section{Statistical analysis}

Statistical analysis was done on Microsoft excel sheet using SPSS 25, Null hypothesis and Paired t-test. It was 
done using Microsoft excel 2010 and Microsoft word 2010 .

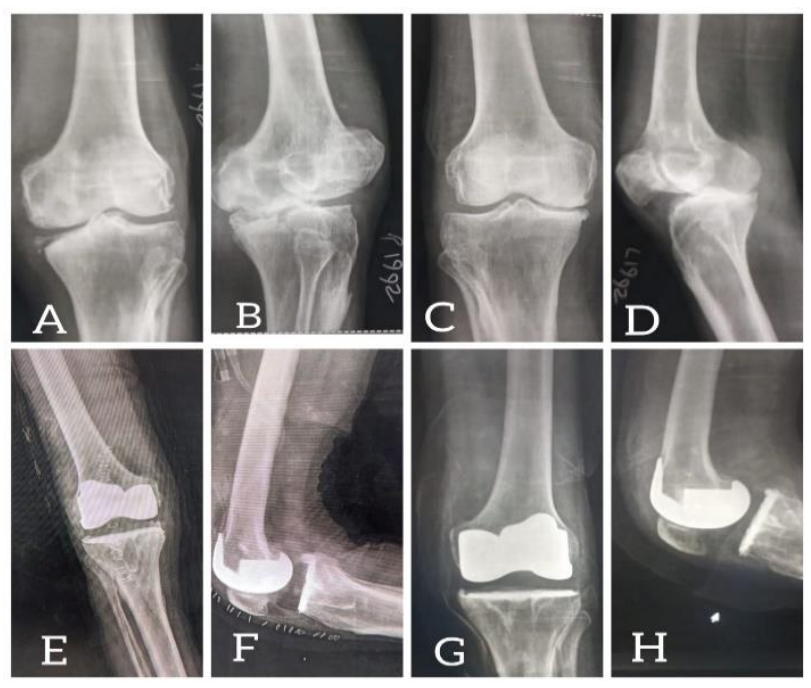

Figure 4: Staged bilateral TKA done on a 75 year old male (A) pre-operative antero-posterior knee X-ray right side, (B) pre-operative lateral knee $X$-ray right side, $(\mathrm{C})$ pre-operative antero-posterior knee $\mathrm{X}$-ray left side, (D) pre-operative lateral knee $\mathrm{X}$-ray left side, (E) post-operative antero-posterior knee $X$-ray right side, $(F)$ post-operative lateral knee $X$-ray right side, (G) post-operative antero-posterior knee X-ray left side and $(H)$ post-operative lateral knee $X$-ray left side.

\section{RESULTS}

The majority of patients were from 66-75 years age group and the mean age was 66 years. Females accounted for $65 \%$ of the total study (Table 2 and 3 ).

Table 2: Age distribution of patients.

\begin{tabular}{|lll|}
\hline $\begin{array}{l}\text { Age of patient } \\
\text { (in years) }\end{array}$ & No. of cases & Percentage \\
\hline $\mathbf{5 1 - 5 5}$ & 1 & 05 \\
\hline $\mathbf{5 6 - 6 0}$ & 3 & 15 \\
\hline $\mathbf{6 1 - 6 5}$ & 4 & 20 \\
\hline $\mathbf{6 6 - 7 0}$ & 7 & 35 \\
\hline $\mathbf{7 1 - 7 5}$ & 5 & 25 \\
\hline
\end{tabular}

Table 3: Sex distribution of patients.

\begin{tabular}{|lll|}
\hline Sex of patient & No. of cases & Percentage \\
\hline Male & 07 & 35 \\
\hline Female & 13 & 65 \\
\hline
\end{tabular}

Table 4: WOMAC score before and after doing TKA.

\begin{tabular}{|llll|}
\hline & Mean (overall) & Pain & Function \\
\hline Pre-op & 79.5 & 16 & 57 \\
\hline Post-op & 42.3 & 07 & 32 \\
\hline
\end{tabular}

Patient's WOMAC score and knee range of motion (ROM) was evaluated and pre-TKA values had a mean of 79.5 and 96.3 degree flexion respectively while after TKA that improved to 42.3 and 108.5 degrees with a p-value less than 0.0001 that is statistically significant (Table 4 and 5).

Table 5: ROM at knee before and after doing TKA.

\begin{tabular}{|lll|}
\hline & Mean (knee flexion) & Standard deviation \\
\hline Pre-op & 96.3 & 6.19 \\
\hline Post-op & 108.5 & 8.70 \\
\hline
\end{tabular}

Out of the 30 knees operated, 26 had no complications. One of the patients developed wound dehiscence for which antibiotics were given but did not improve, hence the poly implant had to be replaced in the $4^{\text {th }}$ week post-operatively. One diabetic patient had a superficial infection which was found to be due to non-compliance to anti-hyperglycemics with an HbA1c level more than $10 \%$. Patient was managed well on antibiotics and insulin with a close monitoring of sugar levels (Figure 3). HbA1c level should be kept below $6 \%$ both pre and post-operatively. In one patient of unilateral TKA, we found a varus deformity seen on X-ray but clinically she is asymptomatic till date. We are keeping close follow-up of the patient and long term observation will be required to comment on it (Figure 2A). One of the patients developed a flexion deformity due to noncompliance of physiotherapy by the patient. Then we put her on hamstring stretching and quadriceps strengthening exercises and she has recovered well with improved knee ROM (Table 6).

Table 6: Post-operative complications following TKA.

\begin{tabular}{|lll|}
\hline Complications & No. of cases & Percentage \\
\hline None & 26 & 86.67 \\
\hline Wound dehiscence & 01 & 3.33 \\
\hline Infection & 01 & 3.33 \\
\hline Varus deformity & 01 & 3.33 \\
\hline Flexion deformity & 01 & 3.33 \\
\hline
\end{tabular}

\section{DISCUSSION}

Arthritis of the knee especially osteoarthritis contributes a significantly towards morbidity of human life. ${ }^{10}$ Daily activities are largely hampered because of this and in absence of any medical treatment to stop its progression, Total knee arthroplasty is on the rise for management of such patients. Still in rural areas, TKA has not been accepted by the people as a mode of treatment who continue taking analgesics from OPDs. ${ }^{11}$ They still consider TKA as the surgery of the rich due to high costs in private corporate hospitals. These patients are at an added disadvantage of developing analgesic abuse nephropathy and gastropathy due to indiscriminate usage of over the counter painkillers. Hence the idea of starting TKA in rural government setup with the expertise available and decreased financial load on the patient as compared to private hospitals. 
In our study we always used disposable drapes for draping in order to reduce infection rates. We found that drapes reduce the rate of infection especially in absence of laminar airflow. ${ }^{12}$ Even in the absence of laminar airflow due to limited infrastructure, the results of TKA done has not been affected. The age-old practice of aseptic precautions-patient optimization and prophylactic antibiotics are at par with laminar airflow. ${ }^{13}$

In our institute, we conducted all surgeries with the only fees being the cost of the implant and drapes. As ours is a government teaching institute and hospital, maintaining some profit was beneficial and important which was done successfully by reducing the hospital stay with no effects on the post-operative management. ${ }^{14,15}$

Another area of fear among people is the relationship between obesity and success of TKA. We found that Obese patients are at no significant disadvantage than non-obese people in terms of post-operative satisfaction. ${ }^{16-18}$

Total hip replacement surgery is advanced as much as possible to give the patient more chances of completing his/her life with just one operation before the wear and tear of the implant necessitates change of implant. But the same does not hold true for total knee replacement. Early operation has shown better postoperative relief of pain and satisfaction in these patients. ${ }^{19,20}$

In our study, for all our patients, we did a staged bilateral knee replacement due to infrastructural constraints. ${ }^{21,22}$ All the patients in whom bilateral knee replacement was done were satisfied after both operations and motivation for second operation was higher than the first one (Figure $2 \mathrm{~B}$, C and 4).

\section{CONCLUSION}

Total knee arthroplasty does reduce knee pain significantly and greatly improves the functional ability of the patient. And to be able to do so in a tertiary government rural setup with no laminar airflow, financial restraints and with such great efficacy and minimal complications bodes well for the vast number of people of rural areas suffering from knee pain in living a pain free active lifestyle. Though this is a very short term follow-up, we intend to do more knee arthroplasties in indicated and deserving patients especially under the government schemes for the poor (Pradhan Mantri Jan Arogya Yojana, Mahatma Jyotiba Phule Jan Arogya Yojana) so that the benefit is extended to a large diaspora of rural community and this procedure is no more a surgery of the rich and a vast population of geriatric age group live a pain free mobile life.

\section{ACKNOWLEDGEMENTS}

We would like to extend our token of appreciation towards our dynamic young dean Dr. Kanan Yelikar who has relentlessly worked for the betterment of our institute and
Professor and Head of the Department Dr. Chandrakant R. Thorat sir for his everlasting support in all our endeavours.

Funding: No funding sources

Conflict of interest: None declared

Ethical approval: Not required

\section{REFERENCES}

1. Pal CP, Singh P, Chaturvedi S, Pruthi KK, Vij A. Epidemiology of knee osteoarthritis in India and related factors. Indian J Orthop. 2016;50(5):518-22.

2. Silverwood V, Blagojevic-Bucknall M, Jinks C, Jordan JL, Protheroe J, Jordan KP. Current evidence on risk factors for knee osteoarthritis in older adults: a systematic review and meta-analysis. Osteoarthritis and Cartilage. 2015;23(4):507-15.

3. Mihalko WM. Arthroplasty of the knee. In: Azhar FM, Beaty JH, Canale ST (eds). Campbell's Operative Orthopaedics. Thirteenth edition. Philadelphia. Elsevier; 2017: 396-534.

4. Mitchell HL, Hurley MV. Management of chronic knee pain: A survey of patient preferences and treatment received. BMC Musculoskelet Disord. 2008;9:123.

5. Drewett RF, Minns RJ, Sibly TF. Measuring outcome of total knee replacement using quality of life indices. Ann R Coll Surg Engl. 1992;74(4):28690.

6. Healy WL, Della Valle CJ, Lorio R, et al. Complications of Total Knee Arthroplasty: Standardized List and Definitions of The Knee Society.2013; Clin Orthop Relat Res 2013;471:21520.

7. David F, Rafael C, Francisco F, Carolina A, Alan G, Jaime C. Clinical and functional outcomes of primary total knee arthroplasty: A South American perspective. Arthroplasty Today. 2019;5(3):368-71.

8. Dowsey MM, Choong PFM. The Utility of Outcome Measures in Total Knee Replacement Surgery. Int J Rheumatol. 2013;2013:506518.

9. Giesinger JM, Hamilton DF, Jost B, Behrend H, Giesinger K. WOMAC, EQ-5D and Knee Society Score Thresholds for Treatment Success After Total Knee Arthroplasty. J Arthroplasty. 2015;30(12):2154-8.

10. Losina E, Walensky RP, Reichmann WM. Impact of obesity and knee osteoarthritis on morbidity and mortality in older Americans. Ann Intern Med. 2011;154(4):217-26.

11. Figaro MK, Russo PW, Allegrante JP. Preferences for Arthritis Care Among Urban African Americans: "I Don't Want to Be Cut". Health Psychol. 2004;23(3):324-9.

12. Kieser DC, Wyatt MC, Beswick A, Kunutsor s, Hooper G. Does the type of surgical drape(disposable versus non-dispoasable) affect the risk of subsequent surgical site infection. Europe PMC. 2018;15(2):56670 . 
13. Teo BJX, Woo YL, Phua JKS, Chong HC, Yeo W, Tan AHC, et al. Laminar flow does not affect risk of periprosthetic joint infection after primary total knee replacement in Asian patients. J Hospital Infect. 2020;104(3):305-8.

14. Healy WL, Rana AJ, Lorio R. Hospital economics of primary total knee arthroplasty at a teaching hospital. Clin Orthop Related Res. 2011;469(1):87-94.

15. Gui O, Zhang X, Liu L, Zhao F, Cheng W, Zhang Y. Cost-utility analysis of total knee arthroplasty for osteoarthritis in a regional medical center in china. Health Economics Rev. 2019;9:15.

16. Stickles, B, Phillips L, Brox WT, Owens B, Lanzer WL. Defining the Relationship between Obesity and Total Joint Arthroplasty. Obesity Res. 2001;9:21923.

17. Deshmukh RG, Hayes JH, I.M. Pinder IM. Does body weight influence outcome after total knee arthroplasty? A 1-year analysis. J Arthroplasty. 2002;17(3):315-9.

18. Yoo JH, Oh HC, Park SH, Kim JK, Kim SH. Does Obesity Affect Clinical and Radiological Outcomes in Minimally Invasive Total Knee Arthroplasty? Minimum 5-Year Follow-up of Minimally Invasive TKA in Obese Patients. Clin Orthop Surg. 2018;10(3):315-21.
19. Fortin PR, Clarke AE, Joseph L, Liang MH, Tanzer M, Ferland D, et al. Outcomes of total hip and knee replacement: preoperative functional status predicts outcomes at six months after surgery. Arthritis Rheum. 1999;42:1722-8.

20. Fortin PR, Penrod JR, Clarke AE, St-Pierre Y, Joseph L, Bélisle P, et al. Timing of total joint replacement affects clinical outcomes among patients with osteoarthritis of the hip or knee. Arthritis Rheumatism. 2002;46:3327-30.

21. Stefánsdóttir A, Lidgren L, Robertsson O. Higher Early Mortality with Simultaneous Rather than Staged Bilateral TKAs: Results From the Swedish Knee Arthroplasty Register. Clin Orthop Relat Res. 2008;466:3066-70.

22. Hutchinson JRM, Parish EN, Cross MJ. A comparison of bilateral uncemented total knee arthroplasty - Simultaneous or staged? J Bone Joint Surg. 2006;88(1):40-3.

Cite this article as: Aziz AMA, Sasidharan NP, Malpani PS. Short term results of total knee arthroplasty in tertiary rural tier three government medical college and hospital. Int J Res Orthop 2020;6:704-9. 